Journal of Thermal Engineering, Vol. 6, No. 5, pp. 712-723, October, 2020

Yildiz Technical University Press, Istanbul, Turkey

\title{
OPTIMIZATION OF BIODIESEL PRODUCTION FROM WASTE COOKING SUNFLOWER OIL BY TAGUCHI AND ANN TECHNIQUES
}

\author{
A. Kolakoti ${ }^{*}$, P.R. Mosa ${ }^{2}$, T. G. Kotaru ${ }^{3}$, M. Mahapatro ${ }^{4}$
}

\begin{abstract}
Sunflower oil is commonly used for cooking purposes. After their repetitive usage, these oils are treated as waste and being dumped. Due to the huge population, the utilization of oil for daily requirements is also high. Every day tonnes of waste cooking oil (WCO) are being discarded which eventually increases environmental pollution. Therefore, WCO was proposed to use for biodiesel production. To achieve maximum biodiesel yield with limited experiments, optimization techniques are popular. In this endeavor, nine experiments were conducted based on Taguchi orthogonal array and Artificial Neural Network (ANN) based feedforward backpropagation was used for validation of the transesterification process. A maximum yield of $92.17 \%$ was achieved at a molar ratio (MR) of 12:1, catalyst concentration (CC) of 15 , reaction temperature at $55^{\circ} \mathrm{C}$ and reaction time for one hour. $\mathrm{CC}$ was observed as the highest influence factor on biodiesel yield. The accuracy of the chosen optimization models was determined by the coefficient of determination which is almost the same for Taguchi (0.9959) and ANN (0.9955). This shows that these models are highly accurate in prediction. As a conclusion, by utilizing WCO for biodiesel production can decrease the overall production cost and the obtained biodiesel properties meet the international standards.
\end{abstract}

Keywords: Waste Cooking Oil, Optimization, Taguchi, ANN, Fuel Properties

\section{INTRODUCTION}

The demand for energy is increasing at a faster rate with the increase in population and it is the prime mover for global civilization. As per the latest statistics by Census Bureau's International database 2019, the present world population is 7.7 billion people and it will reach 8 billion by the year 2025. In that, $17.74 \%$ is contributed by India with a population of 1.37 billion. Due to the huge population in India, the utilization of energy resources especially petroleum-derived fuels are also increasing. As per the latest information provide by energy statistics 2019 [1] by the Government of India, there is a gradual increase in crude oil and natural gas consumption by $4.82 \%$ and its production is in $0.63 \%$. In order to meet this demand, India is importing $5.20 \%$ crude oil from other nations which directly affects the economy of the country.

The rapid utilization of petro-diesels in the transportation sector and their excessive harmful exhaust emissions results in alarming air pollution levels in the country [2]. Now it is a thinking stream to decrease the dependency on foreign imports and at the same time to lower the air pollution. For this purpose, research on clean, reliable and yet economically feasible alternative fuels especially biodiesel is gaining more importance [3-5]. T Vector et al [6] concluded that neat biodiesel and biodiesel with additives can lower the exhaust emissions compared to neat diesel fuel operation. B Prasad Rao et al [7] examine experimentally the effect of Jatropha, Mahua, and Pongamia biodiesels on the performance and exhaust emissions in a diesel engine and conclude that all the selected biodiesel lower the harmful exhaust emissions of NOx and CO compared to the diesel fuel at $3 / 4^{\text {th }}$ and maximum load. The fuel properties of edible and nonedible oil biodiesels are very close to the standard diesel fuel and Cetane number and the molecular oxygen in biodiesel improve the engine performance as investigated by Aditya Kolakoti and B V Appa Rao [8] Literature reveal that biodiesel has the potential to regulate the toxic exhaust emissions from the transportation sector to a greater extent and also provides fuel security for the nations which rely on diesel imports.

This paper was recommended for publication in revised form by Regional Editor Mustafa Kılıç

1,2,3,4 Department of Mechanical Engineering, Raghu Engineering College, Visakhapatnam, India

${ }^{\star}$ E-mail address: aditya.kolakoti@gmail.com

Orcid id: https://orcid.org/0000-0002-7515-8318

Manuscript Received 04 February 2020, Accepted 05 March 2020 
Edible and non-edible oils are the potential feedstocks for biodiesel production. However, 60 to $80 \%$ of the biodiesel production cost depending on the type of feedstocks. The use of edible oils for biodiesel production results in high cost and also self-sufficiency problems in vegetable production. Therefore, the demand for non-edible oils compared to edible oils is significant in developing countries [9]. However, the utilization of waste vegetable oil for biodiesel production can eliminate the obstacles of food vs fuel and high initial raw oil cost for biodiesel production [10]. In general, waste cooking oils (WCO) are discarded after their repeated usage and this will lead to local environmental pollution. Therefore, converting the WCO into biodiesel will mitigate the challenge of environmental pollution and on the other hand decrease the overall production cost of biodiesel because WCO can be obtained for the lowest cost or even for free.

The process of converting raw oil to biodiesel involves lengthy procedure and different process parameters like catalyst type, molar ratio, reaction time, reaction temperature and etc. will influence on biodiesel yield. The maximum biodiesel yield can be achieved by varying the different process parameters. For this purpose, mathematical modelling [11], optimization techniques like Taguchi, Response Surface Method (RSM), Factorial design, and etc. are popular [12]. Among the mentioned techniques Taguchi is a widely used tool for predicting the response factors. Taguchi techniques can investigate the effect of various process parameters by analysis of variance (ANOVA) and contribution factor simultaneously and it can explicate the interaction between them with a minimum number of experimental runs.

The advent of the latest optimization techniques for biodiesel production and the availability of limited research on used sunflower oil for biodiesel production mooted this experimental investigation. The objective of the present investigation is to produce biodiesel from a low-cost feedstock of waste cooking oil (sunflower oil) by using the Taguchi optimization technique and to investigate the influence of process parameters on the biodiesel yield. For this purpose, experiments are conducted based on Taguchi orthogonal design and Artificial Neural Network (ANN) technique is used to validate the experimental and predicted results. Furthermore, the fuel properties of waste cooking oil biodiesel and its blends (B10 to B100) were characterized and compared with standard diesel fuel by following the international standards.

\section{MATERIALS AND PROCEDURE Materials Used}

Waste cooking oil (Sunflower) is collected from local restaurants in Visakhapatnam city to be used as raw material for biodiesel production. The oil is heated to a temperature of $110^{\circ} \mathrm{C}$ to remove the moisture and then filtered with surgical cotton to remove suspended impurities. The filtered oil samples are stored in airtight glass beakers for further analysis. All the chemicals purchased for biodiesel production in this study are of analytical grade. Additive Methanol alcohol (99.10\%), Sulphuric acid (97\%) and the catalyst Sodium hydroxide (anhydrous) were purchased from Merk, Mumbai, India.

\section{Transesterification Process}

Due to the high viscosity of raw oil, the direct application as a fuel in compression ignition engines is restricted. To reduce the high viscosity, different methods like preheating, micro-emulsions, thermal cracking (pyrolysis), transesterification, and etc. are widely used [8]. In this endeavor, Transesterification is employed for biodiesel production. During the transesterification process, the triglycerides react with alcohol which results in biodiesel (fatty acid esters) as the main product and glycerin as a by-product. Due to the presence of high acid value [13] in waste cooking oil (WCO), the separation of glycerides to glycerol is difficult. Therefore, a two-stage acid and base catalyst are used to convert the WCO to biodiesel.

\section{OPTIMIZATION PROCESS \\ Taguchi Experimental Design}

Several factors influence the quality and yield of biodiesel. Among them, process parameters of Molar Ratio (MR), Catalyst Concentration (CC), Reaction time (R-time) and Reaction temperature (R-temp) are of particular interest. It may not be possible to predict the correct combination of process parameters in regular experimentation for maximum biodiesel yield. Therefore, a well-planned design with limited experimentation can eliminate cumbersome 
procedure to a few combinations. For this purpose, the Taguchi optimization technique [14] as suggested by Dr.Genichi Taguchi which is popularly used. Taguchi technique may not investigate every possible combination of process parameters that are involved in the optimization process but, it can reduce the process to limited combinations which makes the data easier to analyze. In this endeavor, four process parameters of MR, CC, R-time, and R-temp are investigated by using a three-level Taguchi's orthogonal array (OA) in Minitab ${ }^{\circledR} 2019$ and nine experiments $\left(\mathrm{L}_{9}\right)$ were conducted based on design matrix. Table.1represents the comprehensive summary as recognized using the equation (1).

$$
N=(L-1) P+1
$$

Where N, L, and P represent the number of experimental runs, levels, and number of chosen parameters in the experimentation respectively.

Table 1. Different ranges of the parameters

\begin{tabular}{|l|l|l|l|l|}
\hline \multirow{2}{*}{ S. No } & \multirow{2}{*}{ Factors } & \multicolumn{3}{|c|}{ Range of levels } \\
\cline { 3 - 5 } & & Low & Medium & Large \\
\hline 1 & Molar Ratio & $6: 1$ & $9: 1$ & $12: 1$ \\
\hline 2 & Catalyst Concentration $(\mathrm{W} \%)$ & 5 & 10 & 15 \\
\hline 3 & Reaction Temperature $\left({ }^{0} \mathrm{C}\right)$ & 45 & 55 & 65 \\
\hline 4 & Reaction Time (Hours) & 1 & 2 & 3 \\
\hline
\end{tabular}

\section{Experimentation Based On the Orthogonal Array Design Matrix}

Based on orthogonal array (OA) design, a sample of one-liter filtered waste cooking (sunflower) oil is poured into a one necked flat-bottomed conical flask fitted with a thermometer. Then the oil is heated to preset temperature with the help of a magnetic stirrer incorporated with a heating pan as shown in figure 1. Due to the presence of high free fatty acids [13] in waste cooking oil (WCO), a two-stage transesterification process is employed in the present investigation. In the first stage (acid catalyzation), methyl alcohol $\left(\mathrm{CH}_{3} \mathrm{OH}\right)$ at various proportions and sulphuric acid $\left(\mathrm{H}_{2} \mathrm{SO}_{4}\right)$ is added to the preheated oil sample in accordance with the designed experimental conditions. The addition of methanol to the sample may result in temperature drop and this can be overcome by adjusting the temperature and agitation speed control in hotplate magnetic stirrer. Then the mixture is allowed to stir continuously by maintaining appropriate temperature (below $65^{\circ} \mathrm{C}$ ) and time as defined (Table.1). The high temperature above $65^{\circ} \mathrm{C}$ may results in methanol evaporation as the boiling point of the methanol is $64.7^{\circ} \mathrm{C}$. Once the reaction time is reached, the mixture is emptied into a separating funnel as shown in figure. 1 and allowed it to settle for 6 hours. Then separate esterified oil (bottom layer) from excess alcohol, sulfuric acid or any other impurities.

In the second stage (alkaline-catalyzed process), methyl alcohol and sodium hydroxide $(\mathrm{NaOH})$ is added to the esterified WCO and the mixture is maintained at predefined time and temperature. After the reaction, the mixture is deposited in a separating funnel for 14 hours to separate the glycerol from methyl ester. A clear separation of glycerin and methyl ester is observed after 14 hours of separation time as shown in figure 1 . The top layer is the methyl ester while the lower layer is glycerin and other impurities that are removed. The leftover methyl ester is washed with hot deionized water multiple times to remove any remaining traces of catalyst or alcohol. The water wash is repeated until $\mathrm{pH}$ of the methyl ester becomes natural. The final sample of waste cooking oil methyl ester (WCOME) is heated up to $110^{\circ} \mathrm{C}$ to remove the water vapor. The obtained fuel sample is stored for further physicochemical property analysis. The experiments are repeated by following the design matrix and the obtained yield is calculated by using the equation (2) and the results are furnished in table 2.

$$
\text { Yield }=\frac{\text { Weight of biodiesel produced }}{\text { Weight of raw oil used }} \times 100
$$


Table 2. Orthogonal array $\mathrm{L}_{9}$ experimental matrix

\begin{tabular}{|l|l|l|l|l|l|}
\hline $\begin{array}{l}\text { Run } \\
\text { order }\end{array}$ & $\begin{array}{l}\text { Molar Ratio } \\
(\mathrm{MR})\end{array}$ & $\begin{array}{l}\text { Catalyst Concentration } \\
(\mathrm{CC})\end{array}$ & $\begin{array}{l}\text { Reaction Temperature } \\
(\text { Rtem })\end{array}$ & $\begin{array}{l}\text { Reaction Time } \\
\text { (Rtime) }\end{array}$ & Yield (\%) \\
\hline 1 & $6: 1$ & 5 & 45 & 1 & 2 \\
\hline 2 & $6: 1$ & 10 & 55 & 3 & 81.20 \\
\hline 3 & $6: 1$ & 15 & 65 & 3 & 89.20 \\
\hline 4 & $9: 1$ & 5 & 55 & 1 & 76.92 \\
\hline 5 & $9: 1$ & 10 & 65 & 2 & 83.30 \\
\hline 6 & $9: 1$ & 15 & 45 & 2 & 90.90 \\
\hline 7 & $12: 1$ & 5 & 65 & 3 & 77.90 \\
\hline 8 & $12: 1$ & 10 & 45 & 1 & 85.49 \\
\hline 9 & $12: 1$ & 15 & 55 & 92.17 \\
\hline
\end{tabular}
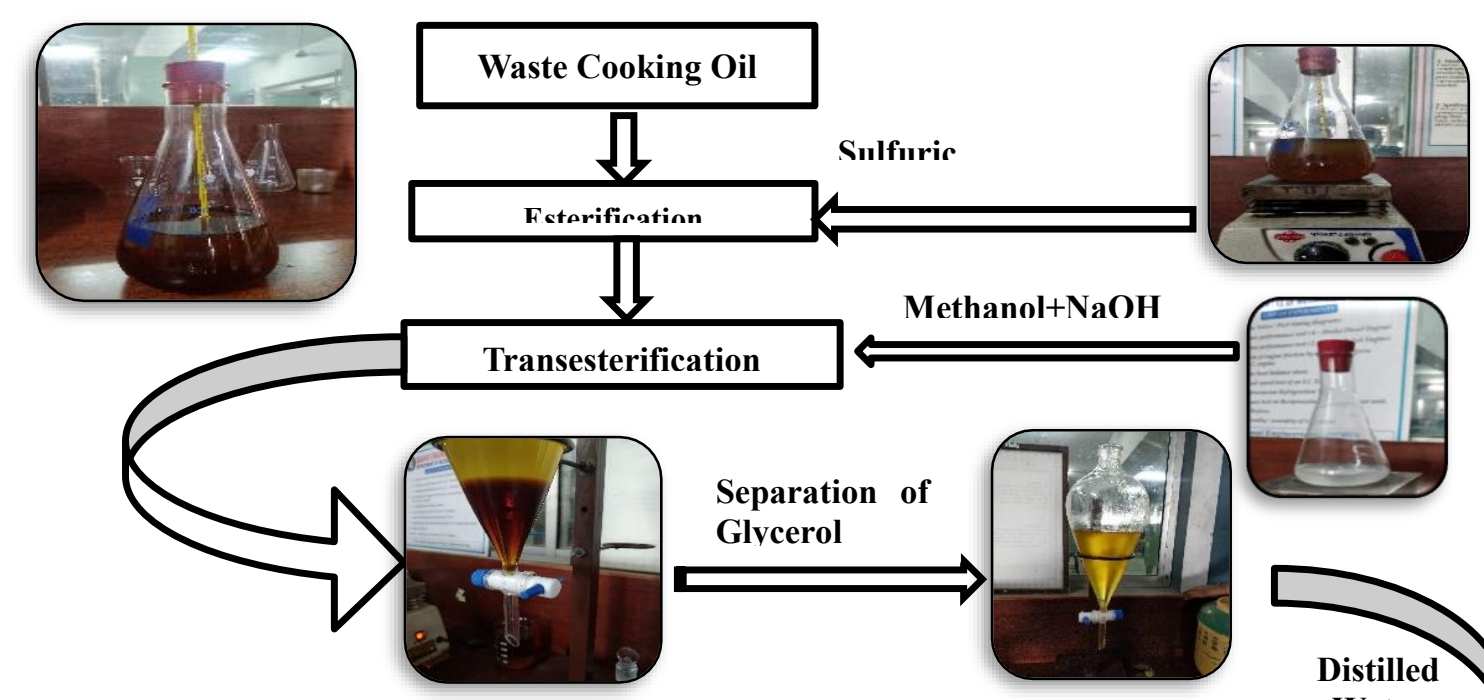

Methanol+NaOH

Glycerol+ Biodiesel
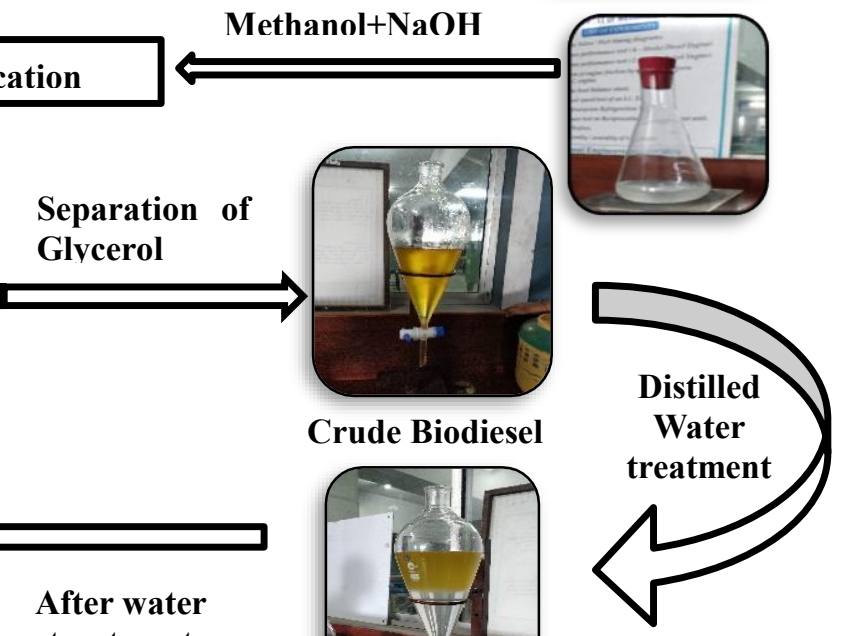

Heating $110^{\circ} \mathrm{C}$

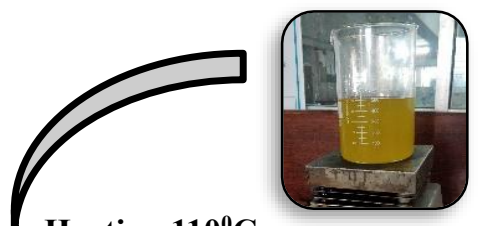

Crude Biodiesel
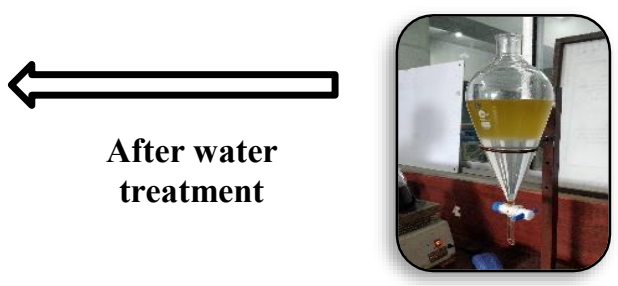

After water

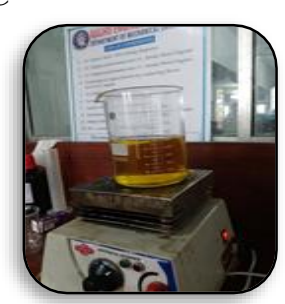

Clear Separation Water and WCO Biodiesel

\section{WCO Biodiesel}

Figure 1. Flow chart of waste cooking oil biodiesel production 
Journal of Thermal Engineering, Technical Note, Vol. 6, No. 5, pp. 712-723, October, 2020

\section{Analysis of Variance (Anova)}

The optimum combination of process parameters can be predicted by Taguchi signal to noise ratio (SNR). The maximum value in SNR represents the optimum response and it is calculated based on three conditions as presented in the equations (3-5). By SNR the optimum response can be predicted but, their contribution and influence of input response on the output cannot be defined. For this purpose, Analysis of variance (ANOVA) test is used. In ANOVA analysis, F-value (Fischer Test) gives the information regarding the significance of the chosen individual parameter that affects the output response and P-value gives the information about the probability of achieving the Fvalue. From equation (6) individual contribution percentage of process parameters can be calculated.

$$
\begin{aligned}
& \text { SNR larger is better response }=-10 \times \log \left(\sum\left(\frac{1}{y^{2}}\right) / n\right) \\
& \text { SNR smaller is better response }=-10 \times \log \left(\sum\left(y^{2}\right) / n\right) \\
& \text { SNR nominal is better response }=10 \times \log \left(\frac{y^{2}}{s^{2}}\right)
\end{aligned}
$$

Where $\mathrm{y}$ is the responses for the given factor level combination, $\mathrm{n}$ is the number of responses in the factor level combination and $\mathrm{s}$ is the standard deviation of the responses for the given factor level combination.

$$
\% \text { of Contribution }=\frac{S S_{f}}{S S_{t}} \times 100
$$

Where $\mathrm{SS}_{\mathrm{f}}$ and $\mathrm{SS}_{\mathrm{t}}$ represent the sum of squares for the $\mathrm{f}^{\text {th }}$ variable and sum of squares for all variables.

\section{RESULTS AND DISCUSSIONS \\ Analysis of Physiochemical Properties}

The physicochemical properties play a vital role in diesel engine combustion phenomena. Poor quality of the fuel will result in excessive harmful exhaust emissions into the atmosphere and at the same time, the reliability of the engine is further decreased due to more engine cylinder vibrations. The kinematic viscosity of the fuel is one of the most important properties which influence the combustion propensity in a diesel engine. High viscous fuel will result in poor atomization with low combustion efficiency and sometimes result in fuel injector clogging. Due to the high viscosity of the raw oil, its direct application is restricted in diesel engines.

The allowable kinematic viscosity of fuel in a standard diesel engine is $5.2 \mathrm{cSt}$ [15] Beyond this, the combustion efficiency of the engine will be decreased. In the present investigation kinematic viscosity for diesel fuel and different blends (B10 to B100) of waste cooking oil, biodiesel is measured with Redwood viscometer by following international standards of American Society for Testing and Materials and European Norms (ASTM D445/ EN ISO 3104). From table (3) it is evident that the kinematic viscosity of the biodiesel is decreased with an increase in diesel quantity and it is also observed that for B10 it is $4.62 \mathrm{cSt}$ and for B100 it is $3.05 \mathrm{cSt}$ is recorded which may be considered as within the limits of aforementioned. For ease of storage and transportation of the fuel, flash and fire points are necessary and they are determined using closed cup Pensky Martens apparatus (ASTM D93, 97 / EN ISO 3679).

The heat of combustion (gross calorific value) for the fuels is determined by using a bomb calorimeter (Widsons). High calorific value in fuel represents the high-power generation to run the engine. It is evident from table (3) $\mathrm{B} 100$ is recorded as the low calorific value $(39.36 \mathrm{MJ} / \mathrm{kg}$ ) and it is gradually increasing with the decrease in the blend percentage in neat diesel fuel. The low calorific value in B100 is due to the presence of saturated and unsaturated fatty acid compositions [16]. The sulfur content in the fuel samples is measured by Wavelength Dispersive X-ray Fluorescence Spectrometry by following the ASTM D2622/ EN ISO 2084 standard. A Pycnometer is used to measure the density of the fuel samples by following the standards of ASTM D 4052/ EN ISO 3675. The cetane number (CN) 
for the blends (B10 to B90) is calculated assuming that the cetane number is a linear combination of the components by using the equation (7).

$$
\text { Blend } \mathrm{CN}=0.9 \times \text { base fuel } \mathrm{CN}+0.1 \times \text { test fuel } \mathrm{CN}
$$

Where base fuel is the diesel fuel $\mathrm{CN}$ (60.2) and test fuel $\mathrm{CN}$ is neat biodiesel (63.63) [17].

Table 3. Different fuel properties with standards

\begin{tabular}{|l|l|l|l|l|l|l|l|l|l|l|l|l|}
\hline Property & $\mathrm{D}$ & $\mathrm{B} 10$ & $\mathrm{~B} 20$ & $\mathrm{~B} 30$ & $\mathrm{~B} 40$ & $\mathrm{~B} 50$ & $\mathrm{~B} 60$ & $\mathrm{~B} 70$ & $\mathrm{~B} 80$ & $\mathrm{~B} 90$ & $\mathrm{~B} 100$ & $\mathrm{STD}$ \\
\hline Viscosity & 2.92 & 3.05 & 3.09 & 3.11 & 3.31 & 3.47 & 3.74 & 3.96 & 4.12 & 4.43 & 4.62 & $\begin{array}{l}\text { EN ISO } \\
3104\end{array}$ \\
\hline $\begin{array}{l}\text { Flash point } \\
\left({ }^{\circ} \mathrm{C}\right)\end{array}$ & 80 & 89 & 98 & 108 & 114 & 116 & 125 & 139 & 152 & 166 & 186 & $\begin{array}{l}\text { EN ISO } \\
3679\end{array}$ \\
\hline $\begin{array}{l}\text { Fire point } \\
\left({ }^{\circ} \mathrm{C}\right)\end{array}$ & 89 & 97.5 & 107 & 116.5 & 125 & 126.5 & 135 & 147 & 161 & 174 & 195 & $\begin{array}{l}\text { ASTMD } \\
97\end{array}$ \\
\hline $\begin{array}{l}\text { Calorific } \\
\text { value } \\
(\mathrm{MJ} / \mathrm{kg})\end{array}$ & 57.0 & 45.83 & 45.06 & 44.01 & 43.4 & 42.45 & 41.38 & 41.16 & 40.89 & 39.72 & 39.36 & ASTMD \\
\hline $\begin{array}{l}\text { Sulfur } \\
\text { content } \\
(\%)\end{array}$ & 36.4 & 33.5 & 30.1 & 27.5 & 21.6 & 17.3 & 13.4 & 11.3 & 6.2 & 2.1 & Nil & EN ISO \\
\hline $\begin{array}{l}\text { Density } \\
\left(\mathrm{g} / \mathrm{m}^{3}\right)\end{array}$ & $\begin{array}{l}0.84 \\
5\end{array}$ & 0.84 & 8.54 & 0.85 & $\begin{array}{l}0.85 \\
9\end{array}$ & 0.866 & 0.871 & 0.879 & 0.881 & 0.885 & 0.887 & $\begin{array}{l}\text { EN ISO } \\
3675\end{array}$ \\
\hline $\begin{array}{l}\text { Cetane } \\
\text { Index }\end{array}$ & 60.2 & 60.53 & 60.84 & 61.24 & $\begin{array}{l}61.5 \\
8\end{array}$ & 61.92 & 62.26 & 62.60 & 62.94 & 63.28 & 63.63 & \\
\hline
\end{tabular}

\section{Analysis of Signal to Noise Ratio (Snr)}

Nine experiments were conducted based on the design matrix of $\mathrm{L}_{9}$ orthogonal array and the output response yield of the biodiesel is presented in the table (4). In order to predict the optimum combination of variable process parameters i.e. molar ratio, catalyst concentration, reaction time, and reaction temperature from the set of 9 experiments an audio concept of signal to noise ratio (SNR) is used. The SNR measures the impact of noise factors on the process parameters and these noise factors cannot be controlled during the experimental process. Therefore, these factors cause variations in response data and need to be considered while analyzing the results. In general, the prediction of SNR is based on three mathematical equations (3-5) Larger is better, Smaller is better and Nominal is better. In this endeavor, the objective is to increase the yield of biodiesel. Therefore, while selecting the target it is chosen Larger is the better in SNR. From the table (4) the maximum value of SNR (39.23) gives the optimum combination of process parameters. From figure (2) it is evident that the maximum yield of the biodiesel is achieved at a molar ratio of 12:1, catalyst concentration of $15 \%$, reaction temperature at $55^{\circ} \mathrm{C}$ and reaction time for 60 minutes.

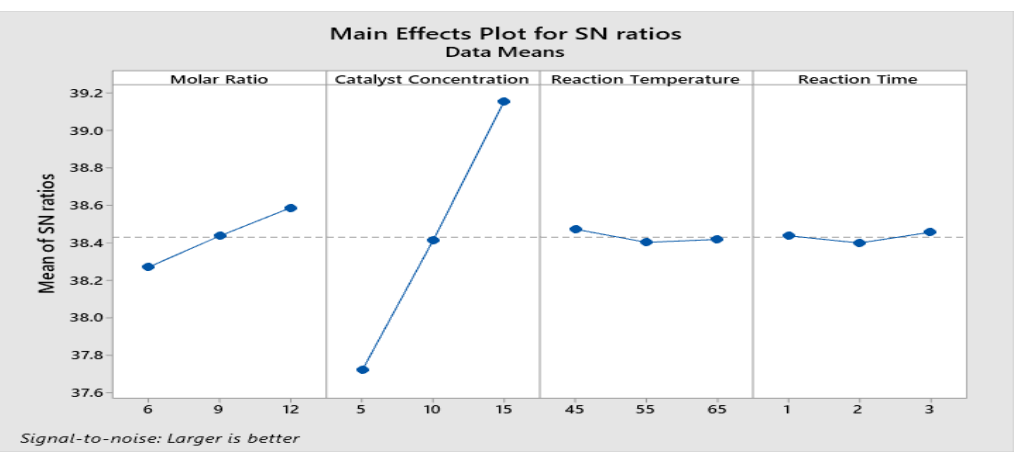

Figure 2. Signal to noise ratio for process parameters 
Journal of Thermal Engineering, Technical Note, Vol. 6, No. 5, pp. 712-723, October, 2020

Table 4. Response output for $\mathrm{L}_{9}$ experiments

\begin{tabular}{|l|l|l|l|l|l|l|l|}
\hline $\begin{array}{l}\text { Run } \\
\text { order }\end{array}$ & $\begin{array}{l}\text { Molar Ratio } \\
(\mathrm{MR})\end{array}$ & $\begin{array}{l}\text { Catalyst } \\
\text { Concentration (CC) }\end{array}$ & $\begin{array}{l}\text { Reaction Temperature } \\
\text { (Rtem) }\end{array}$ & $\begin{array}{l}\text { Reaction Time } \\
(\text { Rtime) }\end{array}$ & Yield (\%) & SNR \\
\hline 1 & $6: 1$ & 5 & 45 & 1 & 75.90 & 37.60 \\
\hline 2 & $6: 1$ & 10 & 55 & 65 & 3 & 81.20 & 38.19 \\
\hline 3 & $6: 1$ & 15 & 55 & 3 & 89.20 & 39.00 \\
\hline 4 & $9: 1$ & 5 & 65 & 1 & 76.92 & 37.72 \\
\hline 5 & $9: 1$ & 10 & 45 & 2 & 83.30 & 38.41 \\
\hline 6 & $9: 1$ & 15 & 65 & 2 & 90.90 & 39.17 \\
\hline 7 & $12: 1$ & 5 & 45 & 3 & 77.90 & 37.83 \\
\hline 8 & $12: 1$ & 10 & 55 & 1 & 85.49 & 38.63 \\
\hline 9 & $12: 1$ & 15 & & & 92.17 & 39.23 \\
\hline
\end{tabular}

After predicting the optimum combination of process parameters, ANOVA analysis is carried out to show the percentage of influence/significance of involved parameters on the desired response. The most significant parameter that affects the biodiesel yield is identified by calculating the contribution factors using the equation (6). From the table (5) it is evident that catalyst concentration is recorded as the highest contribution factor of $94.48 \%$ followed by molar ratio with $4.70 \%$ and reaction temperature of $0.59 \%$. The Reaction time shows less impact on the biodiesel yield and it is recorded as the least contributing factor because once the biodiesel attains the equilibrium condition the yield does not change much with the reaction time. The significance of each process parameter is justified by the contribution factor, on the other hand, F-test and P-test give the reconfirmation. From the table (5) highest F-value for the process parameter of catalyst concentration is 919.24 and the lowest $\mathrm{P}$-value is 0.000 . From the literature [18-20] it is evident that, if the probability (P-value) is below 0.05 then the model is significant. In the present investigation, the $\mathrm{P}$-value is 0.00 which shows that the chosen model is significant.

The accuracy of the linear fit for conducted experiments based on orthogonal design is analyzed by $\mathrm{R}^{2}$ value. In the present experimental investigation $\mathrm{R}^{2}$ of 0.9959 is achieved which is high enough to signify that the model is a good fit for the chosen experiments. The predicted $\mathrm{R}^{2}(0.9696)$ and adjusted $\mathrm{R}^{2}(0.9918)$ values are in reasonable agreement with each other with a difference of 0.022 and the allowable difference is 0.2 [19]. This shows that the model is capable of predicting the response within the acceptable range. The regression equation is also developed for predicting the response yield values for unvisited experiments is formulated in equation (8).

Table 5. ANOVA output response

\begin{tabular}{|l|c|c|c|c|c|c|}
\hline Source & DF & Adj SS & Adj MS & F-Value & P-Value & \% Contribution \\
\hline Molar Ratio & 1 & 14.291 & 14.291 & 45.66 & 0.003 & 4.70 \\
\hline Catalyst Concentration & 1 & 287.734 & 287.734 & 919.24 & 0.000 & 94.48 \\
\hline Reaction Temperature & 1 & 0.595 & 0.595 & 1.90 & 0.240 & 0.595 \\
\hline Reaction Time & 1 & 0.010 & 0.010 & 0.03 & 0.869 & 0.003 \\
\hline Error & 4 & 1.252 & 0.313 & & & 0.412 \\
\hline Total & 8 & 303.882 & & & & \\
\hline
\end{tabular}

Waste cooking oil biodiesel yield $(\%)=66.84+0.5144$ Molar Ratio +1.3850 Catalyst Concentration -0.0315 Reaction Temperature +0.040 Reaction Time. 


\section{Artificial Neural Networks Based Validation Results}

Artificial Neural Networks (ANN) is the best tool to solve complex engineering problems and it is widely used in recent days for predicting, optimization of nonlinear processes [21]. A well-trained ANN is used as a predictive model for a specific application that works based on a biological neural system [22]. ANN consists of a large number of simple processing units called neurons that are interconnected to each other through adoptable synaptic weight. The prediction accuracy of ANN techniques is superior compared to other statistical techniques and these unique features made ANN widely popular. Due to the high accuracy of ANN in this endeavor, an attempt was made to revalidate the output response from the Taguchi optimization technique. If the experimental results and predicted results from ANN are closely matched with each other then, the effectiveness of the optimum combination can be ensured.

\section{Ann Approach}

Taguchi based orthogonal array design matrix from the table. 4 is used to model, train and simulate the ANN by using MATLAB (R2019a) NNTOOL command. The feed-forward backpropagation technique with three layers neurons is used as shown in figure (3) in which, one is input (4 neurons) another two are hidden (20 neurons) and output ( 2 neurons) layers. For training the input layer Molar ratio (MR), Catalyst Concentration (CC), Reaction time ( $\mathrm{R}$ time) and Reaction temperature ( $\mathrm{R}$ temp) are used. This technique forwards the information from the input layer to the output layer via a hidden layer in one direction only. The optimum number of hidden neurons are selected by trial and error method. In the present endeavor, 2 to 20 hidden neurons are investigated for constructing the network architecture. During the training signal received from the trained input data are sent to the hidden layer for further processing. In the hidden layer, TANSIG is used to minimize the Mean Square Error (MSE) and in the final stage, the output generated by ANN is compared with the target results. For better accuracy of the predicted results, TRAINLM is used which can minimize the MSE as shown in the figure (4). The coefficient of correlation is represented by R values, which are used to measure the correlation between actual and predicted values and also measures the direction and strength of the linear relationship between actual and predicted values. From the figure (5) performance of the trained network model is represented by regression value which is 0.9955 and from the Taguchi is 0.9959 . This shows that the chosen model is high accuracy in predicting the responses for the given inputs. Furthermore, figure (6) represents the actual and predicted results for both Taguchi and ANN models which shows that ANN predicted values closely aligned with the Taguchi experimental results.

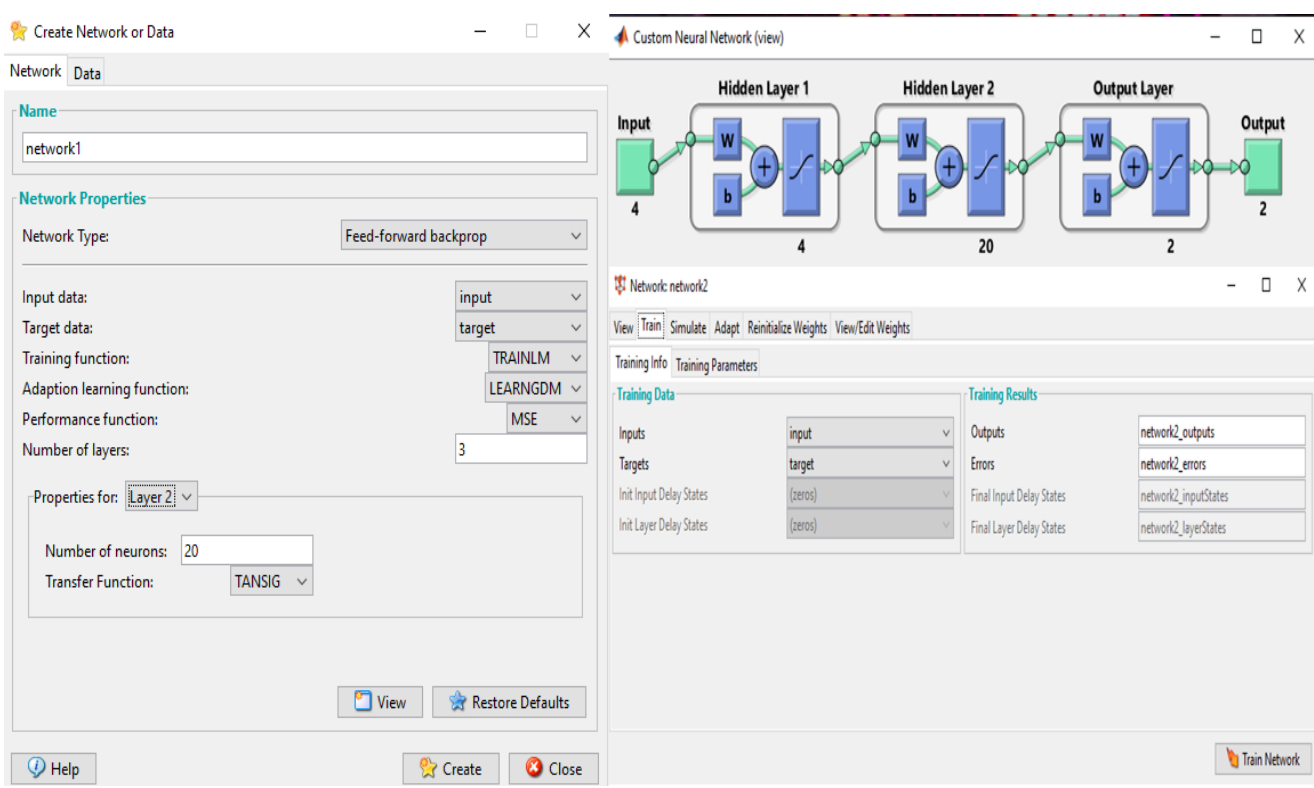

Figure 3. ANN model for development and training 

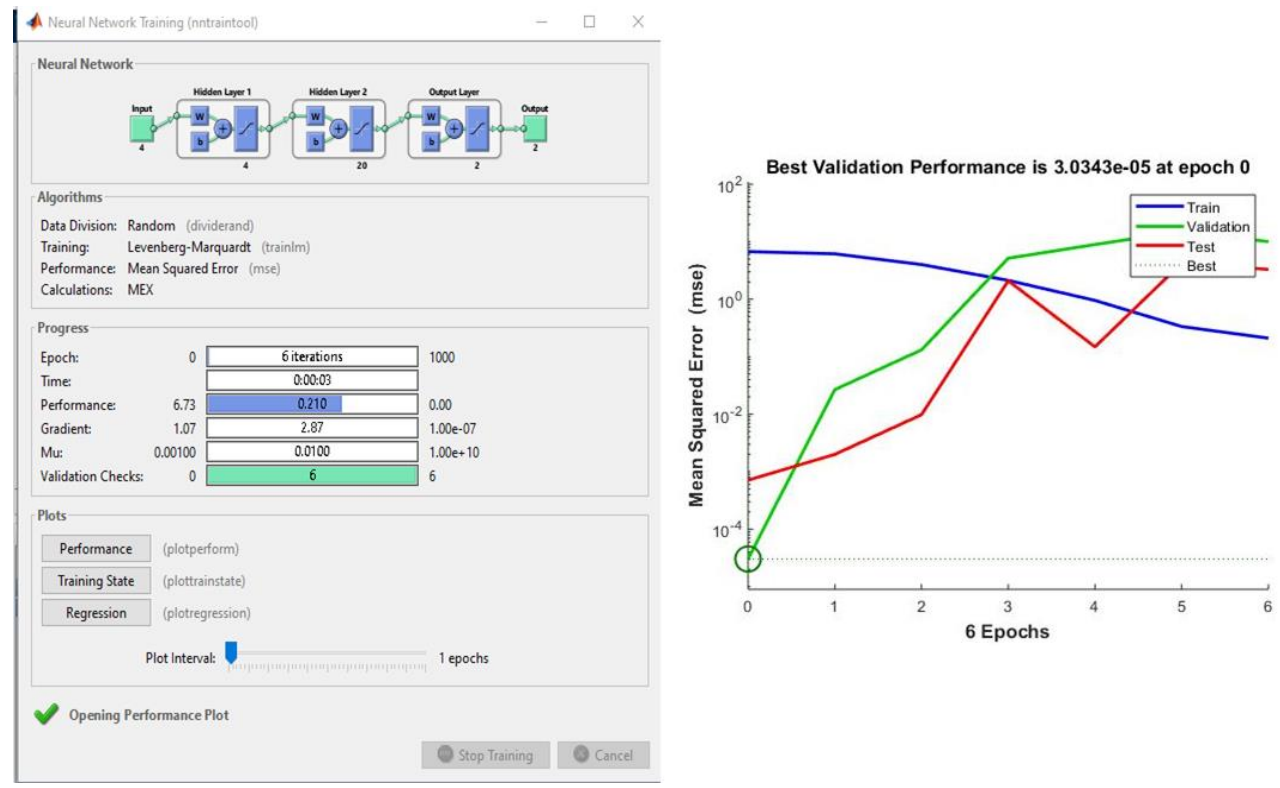

Figure 4. ANN model for training and performance
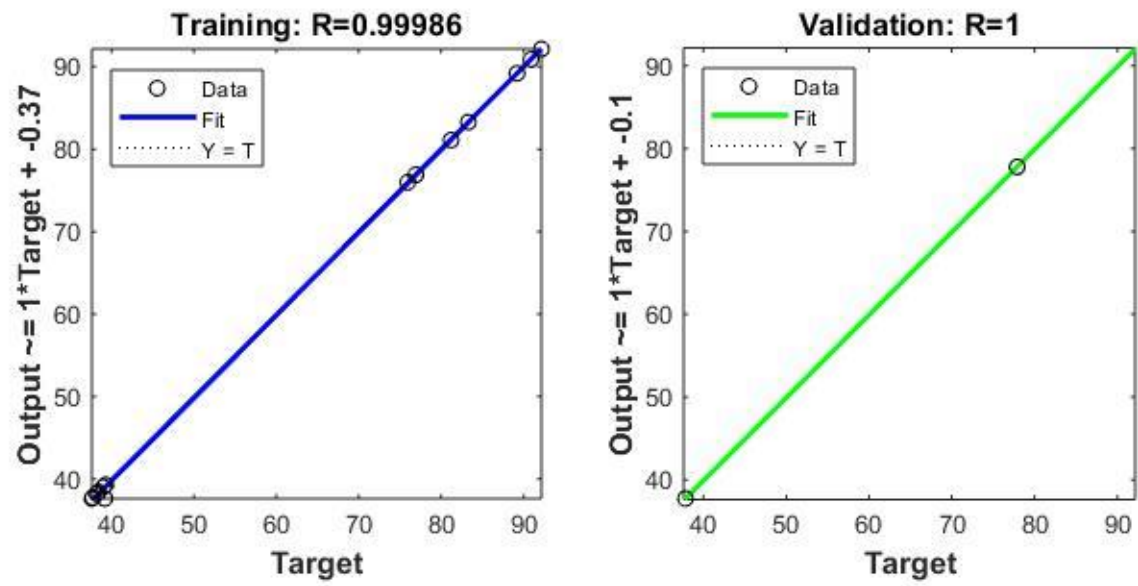

Test: $\mathbf{R}=1$
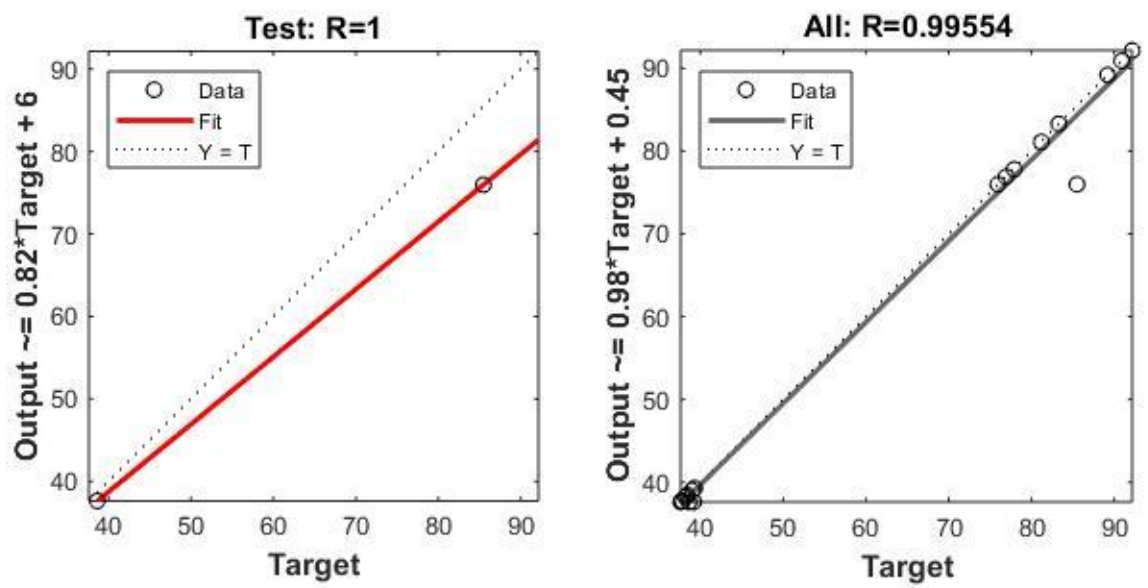

Figure 5. Regression analysis for ANN model 


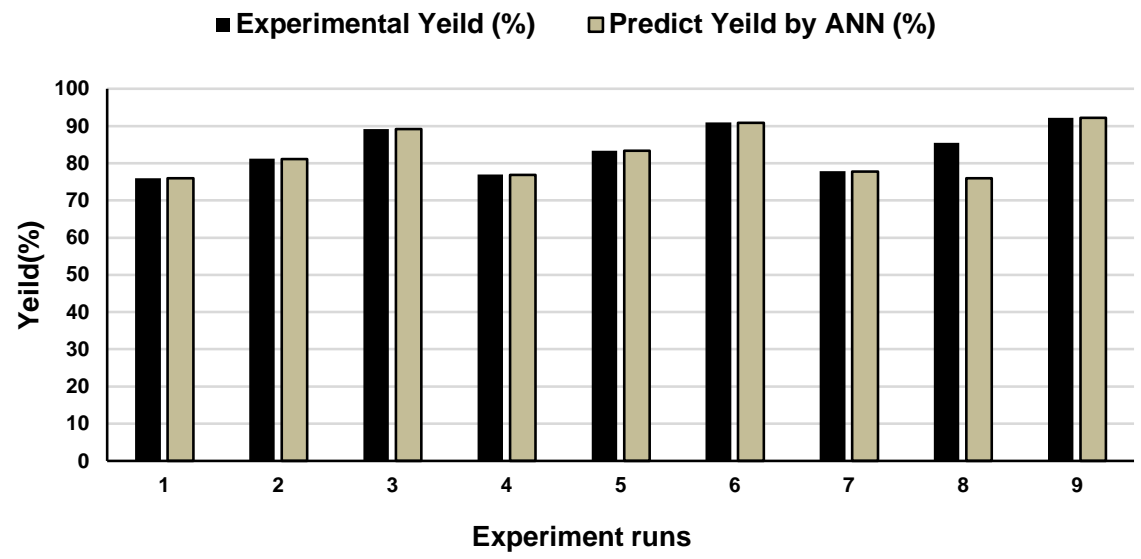

\subsection{Cost Analysis}

Figure 6. Comparison of experimental and ANN model

The major obstacle for biodiesel commercialization is the high production costs. In general, major share for biodiesel production is for raw material (edible or nonedible oils). Due to the high initial cost of raw oil, the overall cost of the production of biodiesel is more. In this research, initial raw oil cost is minimized by using a low-cost feedstock of waste cooking oil which is available abundantly. A model cost calculation is presented in the table (6) which reveal that the cost of one-liter waste cooking oil biodiesel is around Rs $60.70 /$ - which is low compared to the present diesel price in India Rs 73.19/-

Table 6. Cost analysis of waste cooking oil biodiesel

\begin{tabular}{|c|l|c|c|}
\hline S.NO & Parameters & Cost (Rupees) & Cost (USD) \\
\hline 1 & Waste cooking oil $(1000 \mathrm{ml})$ & 00.00 & 0.00 \\
\hline 2 & Methanol $(180 \mathrm{ml})$ & 36.00 & 0.50 \\
\hline 3 & Sulphuric acid $(2.4 \mathrm{ml})$ & 2.40 & 0.033 \\
\hline 4 & Sodium hydroxide $(7 \mathrm{gm})$ & 3.50 & 0.049 \\
\hline 5 & Electricity & 7.80 & 0.11 \\
\hline 6 & Distilled water $(3$ liters $)$ & 7.00 & 0.098 \\
\hline 7 & Labor & 10.00 & 0.14 \\
\hline 7 & Sub total & 66.70 & 0.93 \\
\hline 8 & Revenue from utility of glycerin & 6.00 & 0.084 \\
\hline 9 & Total rupees & 60.70 & 0.85 \\
\hline 10 & Present diesel price & 73.19 & 1.02 \\
\hline
\end{tabular}

\section{CONCLUSIONS}

In this experimental investigation, Taguchi and ANN feed-forward backpropagation models are developed and successfully applied for modeling, simulation and optimization of different process parameters to achieve maximum biodiesel yield from waste cooking oil. Nine experiments were conducted based on the orthogonal array design matrix to convert raw oil to methyl ester. Based on the experimental investigation following conclusions are furnished.

- Waste cooking oil was successfully converted to methyl ester by following two-stage transesterification process. The obtained methyl ester was blended with diesel fuel (B10 to B90) and tested for different fuel properties by following international standards of ASTM-D6751 and EN-14214 
Journal of Thermal Engineering, Technical Note, Vol. 6, No. 5, pp. 712-723, October, 2020

- The highest value in signal to noise ratio (SNR) represents the optimum conditions to achieve the maximum yield of the biodiesel. 92.17\% yield was achieved at a molar ratio of 12:1, catalyst concentration of 15 , reaction temperature at $55^{\circ} \mathrm{C}$ and reaction time for one hour.

- From the analysis of variance (ANOVA), catalyst concentration was recorded as the highest contribution factor $(94.48 \%)$ and the reaction time shows the lowest influence factor on the biodiesel yield.

- F-test and P-test reconfirm that the chosen model was suitable for predicting the optimum process parameters for maximum biodiesel yield.

- From ANN modeling and simulation analysis the chosen feed-forward backpropagation with TRAINLM function predicts the biodiesel yield accurately.

- The results of this experimental investigation conclude that both the Taguchi and ANN models have a high potential for prediction and perform reasonably well. The cost involved in biodiesel production from waste cooking oil was low compared to other feedstocks. Hence, waste cooking oil biodiesel was recommended to use as an alternative fuel in existing diesel engines.

\section{NOMENCLATURE}

$\begin{array}{ll}\text { ANN } & \text { Artificial Neural Network } \\ \text { ANOVA } & \text { Analysis of Variance } \\ \text { BD } & \text { Biodiesel } \\ \text { CC } & \text { Catalyst Concentration } \\ \text { MR } & \text { Molar Ratio } \\ \text { MSE } & \text { Mean Square Error } \\ \text { OA } & \text { Orthogonal Array } \\ \text { SNR } & \text { Signal to Noise Ratio } \\ \text { USD } & \text { United States Dollar } \\ \text { WCO } & \text { Waste Cooking Oil } \\ \text { WCOBD } & \text { Waste Cooking Oil Biodiesel } \\ \text { WCOME } & \text { Waste Cooking Oil Methyl Ester }\end{array}$

\section{CONFLICT OF INTEREST}

The authors declare that they have no conflict of interest.

\section{ACKNOWLEDGMENT}

The authors would like to thank Prof B V Appa Rao for his valuable suggestion on the Transesterification process.

Fuels laboratory, Raghu Engineering College is acknowledged for providing the facilities to undertake the research.

\section{REFERENCES}

[1] Energy statistic 2019: Central statistics office ministry of statistics and programme implementation government of India, New Delhi. Page-13.

[2] Shivakumar Shankar, Harishchandra V Astagi, S R Hotti and Omprakash Hebbal: Effect of exhaust gas recirculation (egr) on performance, emissions and combustion characteristics of a low heat rejection (lhr) diesel engine using pongamia biodiesel. Journal of Thermal Engineering. 2016; 2(5):1007-1016

[3] Siddalingappa R Hotti and Omprakash D Hebbal: Biodiesel production and fuel properties from non-edible champaca (michelia champaca) seed oil for use in diesel engine. Journal of thermal engineering. 2015; 1(1): 330336

[4] Ahmad Abbaszaadeh, Barat Ghobadian, Mohammad Reza Omidkhah and Gholamhassan Najafi: Current biodiesel production technologies: A comparative review. Energy Conversion and Management. https://doi.org/10.1016/j.enconman.2012.02.027/; 2012, [Accepted 2012].

[5] A Abdulvahitoğlu: Evaluation of the fuel quality values of bay laurel (Laurus nobilis L.) oil as a biodiesel feedstock. Biofuels https://doi.org/10.1080/17597269.2016.1257319/;2018, [Accepted 2018]. 
[6] Victor T, Prasad Rao K, Appa Rao B V, Aditya Kolakoti: Experimental investigation on combustion, emissions, performance and cylinder vibration analysis of an IDI engine with RBME along with isopropanol as an additive. Biofuel; https://doi.org/10.1080/17597269.2016.1226723/; 2017, [Accepted 2017].

[7] Bobbili Prasada rao, Aditya Kolakoti and Pudi Sekhar: Exhaust Emission Characteristics of a Three-Wheeler Auto Diesel Engine Fueled with Pongamia, Mahua and Jatropha Biodiesels. Recent Advances in Computer Science and Communications https://doi.org/10.2174/2666255813666191204143202/;2020; [Accepted 2020].

[8] Aditya Kolakoti and BV Appa Rao: A comprehensive review of biodiesel application in IDI engines with property improving additives. I-manager's J Mech Eng 2015; 5(4): 35-45.

[9] S.N.Gebremariam and J.M.Marchetti: Economics of biodiesel production: Review .Energy Conversion and Management , https://doi.org/10.1016/j.enconman.2018.05.002/;2018; [Accepted 2018].

[10] Masoumeh Hajjari, MeisamTabatabaei,Mortaza Aghbashlo and Hossein Ghanavati: A review on the prospects of sustainable biodiesel production: A global scenario with an emphasis on waste-oil biodiesel utilization. Renewable and Sustainable Energy Reviews ,https://doi.org/10.1016/j.rser.2017.01.034/; 2017, [Accepted 2017].

[11] M Kiliç, A Abdulvahitoğlu: Numerical Investigation of Heat Transfer at a Rectangular Channel with Combined Effect of Nano fluids and Swirling Jets in a Vehicle Radiator. Thermal Science;https://doi.org/10.2298/TSCI180816294K/; 2019, [Accepted 2019].

[12] Nabanita Banerjee,Souvik Barman, Gour Saha and Tushar Jash: Optimization of process parameters of biodiesel production from different kinds of feedstock. Materials today Proceedings https://doi.org/10.1016/j.matpr.2018.11.033/; 2018, [Accepted 2018].

[13] Omar Aboelazayem, Mamdouh Gadall, Basudeb Saha: Valorisation of high acid value waste cooking oil into biodiesel using supercritical methanolysis: Experimental assessment and statistical optimisation on typical Egyptian feedstock. Energy https://doi.org/10.1016/j.energy.2018.07.194/; 2018; [Accepted 2018].

[14] Sumit H.Dhawane,Bisheswar Karmakar,Shubham Ghosh,Gopinath Halder: Parametric optimisation of biodiesel synthesis from waste cooking oil via Taguchi approach. Journal of Environmental Chemical Engineering https://doi.org/10.1016/j.jece.2018.05.053/;2018; [Accepted 2018].

[15] Evangelos G.Giakoumis and Christos K.Sarakatsanis: Estimation of biodiesel cetane number, density, kinematic viscosity and heating values from its fatty acid weight composition. Fuel, https://doi.org/10.1016/j.fuel.2018.02.187/;2018; [Accepted 2018].

[16] Aditya Kolakoti \& B. V. Appa Rao: Effect of fatty acid composition on the performance and emission characteristics of an IDI supercharged engine using neat palm biodiesel and coconut biodiesel as an additive, Biofuels, https://doi.org/10.1080/17597269.2017.1332293/;2019; [Accepted 2019].

[17] K.A.Abed, A.K.El Morsi, M.M.Sayed,A.A. ElShaib and M.S.Gad: Effect of waste cooking-oil biodiesel on performance and exhaust emissions of a diesel engine. Egyptian Journal of Petroleum https://doi.org/10.1016/j.ejpe.2018.02.008/;2018; [Accepted 2018].

[18] Sumit H. Dhawane, Tarkeshwar Kumar, Gopinath Halder: Biodiesel synthesis from Hevea brasiliensis oil employing carbon supported heterogeneous catalyst: Optimization by Taguchi method. Renewable Energy, http://dx.doi.org/10.1016/j.renene.2015.12.027/;2016; [Accepted 2016].

[19] Sharath Satya, Aditya Kolakoti, Naga Raju B, Shyam Sundar R and Ranga Rao: Optimization of palm methyl ester and its effect on fatty acid compositions and cetane number. Mathematical Models in Engineering, https://doi.org/10.21595/mme.2019.20469/;2019; [Accepted 2019].

[20] Y Rajesh, Aditya Kolakoti, B.G. Chandra Sheakar and J Bhargavi: Optimization of biodiesel production from waste frying palm oil using definitive screening design. International Journal of Engineering, Science and Technology. Vol 11(2),2019, pp 48-57.

[21] Rajendra M, Jena PC, Raheman H: Prediction of optimized pretreatment process parameters for biodiesel production using ANN and GA. Fuel, https://doi.org/10.1016/j.fuel.2008.12.008/;2009; [Accepted 2009].

[22] Selvaraju Sivamani, Selvaraj Selvakumar, Karthik Rajendran \& Shanmuga prakash Muthusamy: Artificial neural network-genetic algorithm-based optimization of biodiesel production from Simarouba glauca. Biofuels, https://doi.org/10.1080/17597269.2018.1432267/;2019; [Accepted 2019]. 